\title{
Perbaikan Probabilitas Lexical Model untuk Meningkatkan Akurasi Mesin Penerjemah Statistik
}

\author{
Soni Mandira ${ }^{1}$, Herry Sujaini ${ }^{2}$, Arif Bijaksana Putra Negara ${ }^{3}$. \\ Program Studi Teknik Informatika Fakultas Teknik Universitas Tanjungpura ${ }^{123}$ \\ e-mail: sonimandira@icloud.com ${ }^{1}$, herry_sujaini@yahoo.com ${ }^{2}$, arifbpn@gmail.com ${ }^{3}$
}

\begin{abstract}
Abstrak-Bahasa merupakan alat komunikasi yang digunakan seseorang untuk menyampaikan ide, gagasan, konsep atau perasaan kepada orang lain. Ragam bahasa yang dimiliki setiap orang berbeda, hal ini dapat menghambat pertukaran informasi karena orang lain tidak memahami maksud dan tujuan yang ingin disampaikan. Mesin Penerjemah Statistik (Statistical Machine Translation) merupakan sebuah pendekatan mesin penerjemah dengan hasil terjemahan yang dihasilkan atas dasar model statistik yang parameter-parameternya diambil dari hasil analisis korpus paralel. Tujuan yang ingin dicapai dalam penelitian ini adalah melakukan perbaikan probabilitas lexical model pada mesin penerjemah statistik bahasa Jawa ke bahasa Indonesia untuk meningkatkan nilai akurasi hasil terjemahan. Pengujian dilakukan dengan membandingkan nilai akurasi hasil terjemahan sebelum dan setelah perbaikan probabilitas lexical model. Penelitian menggunakan korpus paralel sebanyak 5108 kalimat. Pengujian dilakukan dengan dua cara, yaitu pengujian otomatis menggunakan Bilingual Evaluation Understudy (BLEU) dan pengujian oleh ahli bahasa Jawa. Hasil dari pengujian adalah terdapat peningkatan persentase nilai BLEU sebesar $0.30 \%$ pada pengujian otomatis dan $10.69 \%$ pada pengujian oleh ahli bahasa.
\end{abstract}

Kata Kunci- BLEU score, korpus paralel, lexical model, mesin penerjemah statistik.

\section{PENDAHULUAN}

Bahasa merupakan alat komunikasi yang digunakan seseorang untuk menyampaikan ide, gagasan, konsep atau perasaan kepada orang lain. Adapun fungsi bahasa sebagai alat komunikasi yaitu sarana penyampaian informasi kepada orang lain baik secara lisan maupun tulisan mengenai apa yang ingin disampaikan sebagai media mengekspresikan diri, perasaan, pikiran, keinginan, serta kebutuhan agar orang dapat mengerti maksud dan tujuan yang diinginkan tanpa menghindari tata bahasa yang sudah ada. Berdasarkan Sensus Penduduk pada tahun 2010, dari berbagai bahasa yang terdapat di Indonesia, bahasa Jawa menempati urutan pertama penggunaan bahasa daerah terbanyak yang digunakan sehari-hari dengan persentase $31,79 \%$ (68.044.660 juta jiwa) dari total penduduk Indonesia [1].

Bahasa Jawa sebagai bahasa terbesar di Indonesia merupakan aset berharga yang harus dipertahankan agar bahasa Jawa tidak terlupakan dalam kehidupan sehari-hari, seperti yang dilakukan Pemerintah Provinsi Jawa Tengah dengan menjadikan bahasa Jawa sebagai pelajaran muatan lokal [2]. Upaya pelestarian bahasa Jawa juga telah dilakukan dengan memasukkan penggunaan bahasa Jawa dalam acara pada media massa dan media elektronik. Beberapa upaya tersebut dinilai belum menjadi solusi optimal dikarenakan faktor media massa yang meracuni bahasa daerah dan bahasa Indonesia dengan maraknya penggunaan dialek Jakarta.

Berdasarkan faktor-faktor yang telah dijabarkan, untuk menghindari terjadinya kemerosotan penggunaan bahasa daerah, salah satu caranya adalah dengan mesin penerjemah statistik. Mesin penerjemah statistik (Statistical Machine Translation) merupakan sebuah pendekatan mesin penerjemah dengan hasil terjemahan yang dihasilkan atas dasar model statistik yang parameter-parameternya diambil dari hasil analisis korpus paralel [3].

Salah satu model yang digunakan untuk menghasilkan hasil terjemahan adalah lexical model yang dihasilkan melalui proses training secara otomatis dari korpus paralel. Lexical model berisi kosakata dari bahasa sumber yang memiliki arti pada bahasa sasaran ataupun sebaliknya (leksikal). Setiap kosakata yang dihasilkan memiliki jumlah probabilitas sebesar 1.0 yang terbagi dalam tiap arti. Lexical model yang diperoleh dari proses training kurang maksimal karena terdapat banyak kosakata yang tidak sesuai dengan artinya. Oleh karena itu diperlukan perbaikan lexical model secara manual dengan bantuan oleh ahli bahasa.

Berdasarkan permasalahan diatas, maka pada penelitian ini dilakukan perbaikan probabilitas lexical model untuk meningkatkan akurasi mesin penerjemah statistik bahasa Jawa - bahasa Indonesia.

\section{URAIAN PENELITIAN}

\section{A. Mesin Penerjemah Statistik}

Mesin penerjemah statistik merupakan salah satu jenis mesin penerjemah dengan menggunakan pendekatan statistik. Menurut Christoper D Manning dan Hinrich Schutze, dalam statistical machine translation terdapat tiga buah komponen yang terlibat dalam proses penerjemahan kalimat dari suatu bahasa ke bahasa lain, yaitu language model, translation model, dan decoder seperti yang tertera pada Gambar 1 [4].

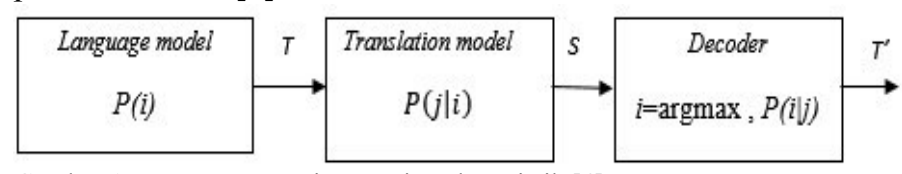

Gambar 1. Komponen mesin penerjemah statistik [4]

Language model digunakan pada aplikasi Natural Language Processing seperti speech recognition, part-ofspeech tagging dan syntactic parsing. Language model statistik menetapkan probabilitas $\mathrm{P}\left(\mathrm{W}_{1, \mathrm{n}}\right)$ ke serangkaian $n$ kata dengan means sebuah distribusi probabilitas. 
Translation model merupakan salah satu komponen penting pada statistical machine translation dalam proses penerjemahan yang membagi kalimat bahasa asal menjadi barisan frase, menerjmahkan setiap frase ke tujuan, dan reordering.

Komponen terakhir dari mesin penerjemah statistik adalah decoder yang berfungsi untuk mencari teks dalam Bahasa tujuan yang memiliki probabilitas paling besar dengan pertimbangan translation model dan language model.

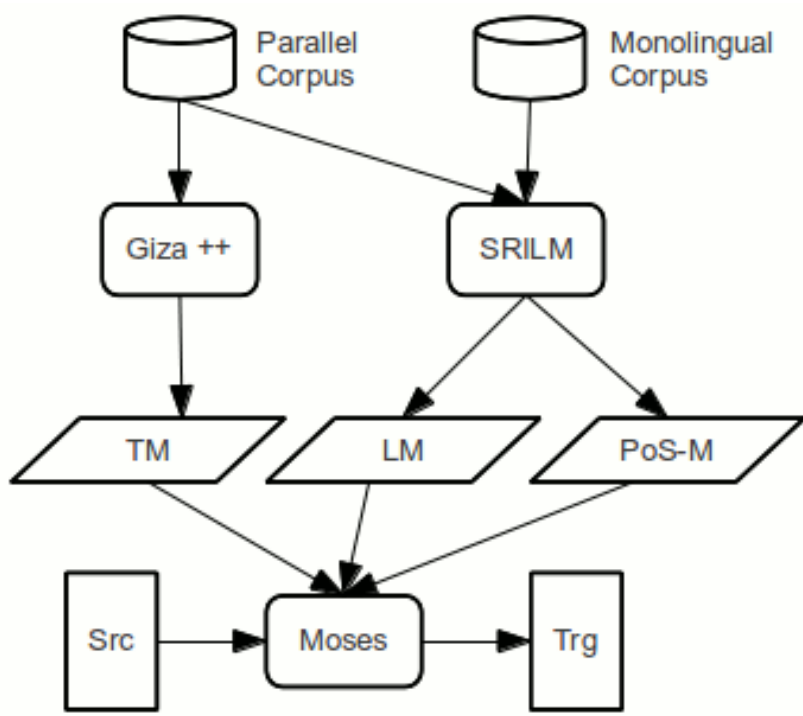

Gambar 2. Arsitektur mesin pnerjemah statistik Moses [5]

Gambar 2 merupakan arsitektur sistem dari mesin penerjemah statistik Moses. Menurut Herry Sujaini dan Arif B.P.N, sumber data utama yang dipergunakan adalah parallel corpus dan monolingual corpus. Proses training terhadap parallel corpus menggunakan GIZA++ menghasilkan translation model (TM). Proses training terhadap bahasa target pada parallel corpus ditambah dengan monolingual corpus bahasa target menggunakan SRILM menghasilkan language model (LM), sedangkan PoS model (PoS-M) dihasilkan dari bahasa target pada parallel corpus yang setiap katanya sudah ditandai dengan PoS. TM, LM dan PoS-M digunakan untuk menghasilkan decoder Moses. Selanjutnya Moses digunakan sebagai mesin penerjemah untuk menghasilkan bahasa target dari input kalimat dalam bahasa sumber [5].

\section{B. Moses}

Moses adalah salah satu Mesin Penerjemah Statistik yang memungkinkan untuk menerjemahkan secara otomatis setiap pasangan bahasa. Moses digunakan untuk melatih model statistik teks terjemahan dari bahasa sumber ke bahasa sasaran. Saat melakukan penerjemahkan bahasa, Moses membutuhkan korpus dalam dua bahasa, bahasa sumber dan bahasa sasaran. Moses dirilis di bawah lisensi LGPL (Lesser General Public License) dan tersedia sebagai kode sumber dan binari untuk Windows dan Linux. Perkembangannya didukung oleh proyek EuroMatrix, dengan pendanaan oleh European Commission [6].

\section{Korpus}

Korpus didefinisikan sebagai koleksi atau sekumpulan contoh teks tulis atau lisan dalam bentuk data yang dapat dibaca dengan menggunakan seperangkat mesin dan dapat diberi catatan berupa berbagai bentuk informasi linguistik [7]. Korpus dapat diklasifikasikan ke dalam delapan jenis, yaitu korpus khusus (specialised corpus), korpus umum (general corpus), korpus komparatif (comparable corpus), korpus paralel (parallel corpus), korpus pemelajar (learner corpus), korpus pedagogis (pedagogic corpus), korpus historis atau diakronis (historical or diachronic corpus), dan korpus monitor (monitor corpus) [8]. Berdasarkan jenis korpus tersebut, untuk penelitian ini penulis akan fokus pada korpus paralel.

\section{Automatic Evaluation}

Sistem evaluasi otomatis yang populer saat ini adalah BLEU (Bilingual Evaluation Understudy). BLEU adalah sebuah algoritma yang berfungsi untuk mengevaluasi kualitas dari sebuah hasil terjemahan yang telah diterjemahkan oleh mesin dari satu bahasa alami ke bahasa lain. BLEU mengukur modified n-gram precission score antara hasil terjemahan otomatis dengan terjemahan rujukan dan menggunakan konstanta yang dinamakan brevity penalty.

Nilai BLEU didapat dari hasil perkalian antara brevity penalty dengan rata-rata geometri dari modified precision score. Semakin tinggi nilai BLEU, maka semakin akurat dengan rujukan. Sangat penting untuk diketahui bahwa semakin banyak terjemahan rujukan per kalimatnya, maka akan semakin tinggi nilainya. Untuk menghasikan nilai BLEU yang tinggi, panjang kalimat hasil terjemahan harus mendekati panjang dari kalimat referensi dan kalimat hasil terjemahan harus memiliki kata dan urutan yang sama dengan kalimat referensi. Rumus BLEU sebagai berikut [9]:

$B P_{B L E U}=\left\{\begin{array}{c}1 \quad \text { if } c>r \\ e^{(1-r / c)} \text { if } c \leq r\end{array}\right.$

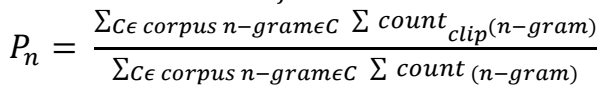

$\mathrm{BLEU}=B P_{B L E U} \cdot e^{\sum_{n-1}^{N} w_{n} \log p_{n}}$

Keterangan:

$\mathrm{BP}=$ brevity penalty

c = jumlah kata dari hasil terjemahan otomatis

$\mathrm{r} \quad=$ jumlah kata rujukan

$P_{n}=$ modified precission score

$w_{n}=1 / \mathrm{N}$ (standar nilai $\mathrm{N}$ untuk BLEU adalah 4$)$

$p_{n}=$ jumlah $n$-gram hasil terjemahan yang sesuai dengan rujukan dibagi jumlah n-gram hasil terjemahan

\section{HASIL DAN DISKUSI}

\section{A. Data Penelitian}

Data penelitian berupa buku cerita rakyat yang berasal dari Jawa Tengah dan Yogyakarta. Dokumen beserta cerita tersebut selanjutnya diolah menjadi korpus teks paralel bahasa Indonesia dan bahasa Jawa. Adapun jumlahnya yaitu 5108 pasangan kalimat korpus paralel bahasa Jawa dan bahasa Indonesia. Dengan jumlah 6961 token untuk korpus bahasa Jawa dan 5536 token untuk bahasa Indonesia.

\section{B. Implementasi Mesin Penerjemah Statistik Jawa ke Bahasa Indonesia}

1. Implementasi SRILM

Model bahasa digunakan sebagai sumber pengetahuan berbasis teks dengan nilai-nilai probabilistik. Penelitian ini 
menggunakan n-gram sebagai language model. Model bahasa dibangun dengan tools SRILM. Model bahasa akan menghasilkan output dengan format file *.lm. Gambar 3 merupakan tabel model bahasa yang dihasilkan oleh SRILM pada mesin penerjemah statistik bahasa Jawa - Bahasa Indonesia.

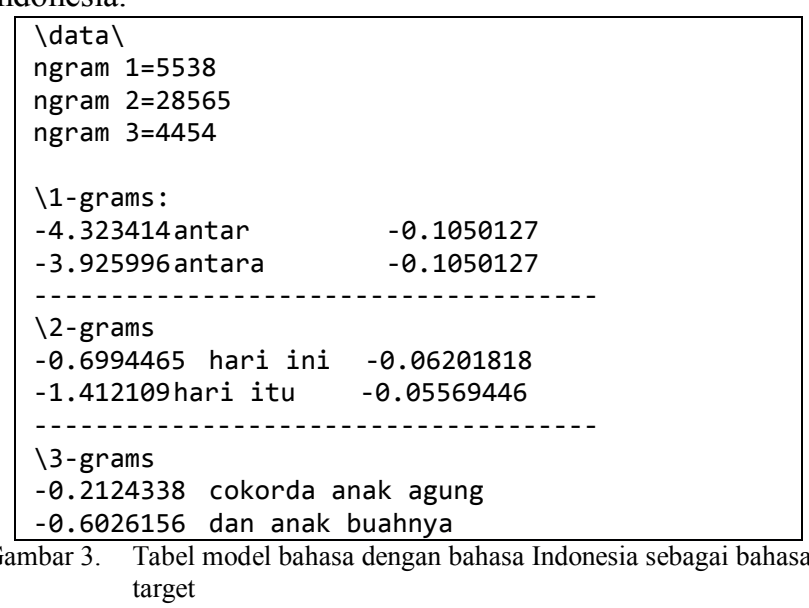

\section{Implementasi Giza++ Untuk Pemodelan Translasi}

Model translasi digunakan untuk memasangkan teks input dalam bahasa sumber dengan teks output dalam bahasa target. Model translasi dibangun dengan tools Giza++. Proses pemodelan translasi oleh Giza++ menghasilkan dokumen vocabulary corpus, word alignment dan lexical model table. Dokumen-dokumen tersebut terdapat dalam folder "train" yang didalamnya terdapat 4 file yaitu "corpus, giza.jw-id, giza.id-jw dan model".

\begin{tabular}{|ll|}
\hline 1 UNK & 0 \\
2 sing & 1244 \\
3 ora & 811 \\
4 iku & 773 \\
5 dheweke & 767 \\
6 ing & 646 \\
7 lan & 592 \\
8 wis & 517 \\
9 ana & 475 \\
10 karo & 445 \\
\hline
\end{tabular}

Gambar 4. Dokumen vocabulary corpus bahasa Jawa

Gambar 4 merupakan isi dari dokumen vocabulary corpus. Angka 1 sampai 10 pada dokumen vocabulary corpus merupakan uniq id untuk setiap data token, sedangkan angka disebelah kanan token menunjukkan frekuensi kemunculan. Vocabulary corpus yang dihasilkan mesin penerjemah bahasa Jawa - bahasa Indonesia terdiri dari 6961 token untuk korpus bahasa Jawa dan 5536 token untuk bahasa Indonesia.

\footnotetext{
\# Sentence pair (2381) source length 5 target length

5 alignment score : 0.0729788

ora ana sing bisa ditindakake

NULL ( \{\}$)$ tidak ( $\{1\}$ ) ada (\{ 2$\})$ yang ( $\left\{\begin{array}{l}3 \\ 3\end{array}\right)$

bisa ( $\{4\}$ ) dilakukan ( $\{5\}$ )

Gambar 5. Dokument alignment bahasa Jawa - bahasa Indonesia
}

Gambar 5 merupakan dokumen alignment Bahasa Jawa - bahasa Indonesia yang memiliki tiga baris kalimat. Baris pertama berisi letak kalimat target (2381) dalam korpus, panjang kalimat sumber (5), panjang kalimat target (5) dan skor alignment. Baris kedua merupakan bahasa sumber dan baris ketiga merupakan alignment kalimat bahasa target terhadap kalimat bahasa sumber. Kata "dilakukan" ( $\left\{\begin{array}{l}5 \\ \text { S }\end{array}\right)$ memiliki makna bahwa kata "dilakukan" pada kalimat bahasa target, di-align ke kata kelima pada kalimat bahasa sumber yaitu "ditindakake".

\begin{tabular}{|ll|}
\hline senyap trintim & 1.0000000 \\
rumahnya ngomahe & 1.0000000 \\
lamaranmu lamaranmu & 1.0000000 \\
pojok pojok & 1.0000000 \\
perang perange & 1.0000000 \\
\hline Gambar 6. Tabel lexical model mesin penerjemah bahasa Jawa - bahasa \\
\end{tabular}

Gambar 6 merupakan tampilan dari tabel lexical model pada mesin penerjemah statistik bahasa Jawa - bahasa Indonesia. Proses lexical translation table oleh Giza++ akan menghasilkan tabel translasi lexical model yang terdiri dari tabel kata yang berisi kosakata dari bahasa sumber yang memiliki makna pada bahasa sasaran ataupun sebaliknya (leksikal). Setiap kosakata yang dihasilkan memiliki jumlah probabilitas sebesar 1.0 yang terbagi dalam beberapa makna.

\section{Pengujian Hasil Terjemahan Mesin Translasi}

Pengujian hasil translasi dilakukan dengan cara pengujian otomatis dari mesin penerjemah. Pengujian otomatis dari mesin penerjemah menghasilkan keluaran berupa nilai akurasi yang dihasilkan oleh BLEU (Billingual Evaluation Understudy). Hasil pengujian ini nantinya akan menjadi parameter untuk membandingkannya dengan hasil pengujian setelah dilakukan perbaikan lexical model.

Langkah pada pengujian otomatis, korpus yang akan diuji terlebih dahulu melalui langkah translasi otomatis yang akan memberikan output berupa korpus dalam bahasa target yang telah diterjemahkan oleh mesin. Korpus uji yang digunakan pada tahap ini berjumlah 5108.

Setelah membuat output berupa hasil translasi otomatis dari mesin penerjemah, langkah selanjutnya adalah mendapatkan skor dari output dengan cara membandingkan output tersebut dengan korpus manual bahasa target yang telah dibuat sebelumnya.

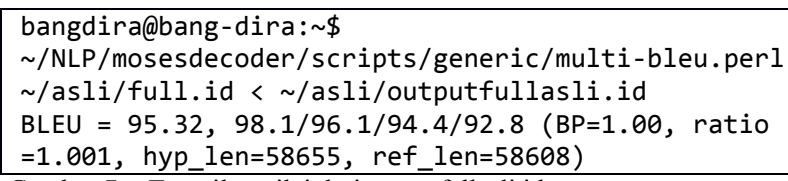

Gambar 7 merupakan sintaks untuk memperoleh nilai BLEU dan hasilnya yang menampilkan nilai dari ouputfullasli.id sebesar $95.32 \%$.

\section{Perbaikan Probabilitas Lexical Model}

Setelah mendapatkan nilai awal dari korpus uji, maka langkah selanjutnya adalah melakukan perbaikan probabilitas lexical model. Perbaikan probabilitas lexical model dilakukan penulis dengan menggunakan aplikasi bantu yang telah dibuat sebelumnya.

Langkah awal perbaikan probabilitas lexical model, dilakukan perbaikan dengan kelipatan sekitar 50 perbaikan lexical model dengan menyimpannya pada tiap-tiap folder yang berbeda namun dengan nama file yang sama, yakni lex.f2e. Perbaikan lexical model yang dilakukan meliputi, 
- menghapus kata yang tidak sesuai dengan arti seperti yang ditampilkan pada gambar 8 ,

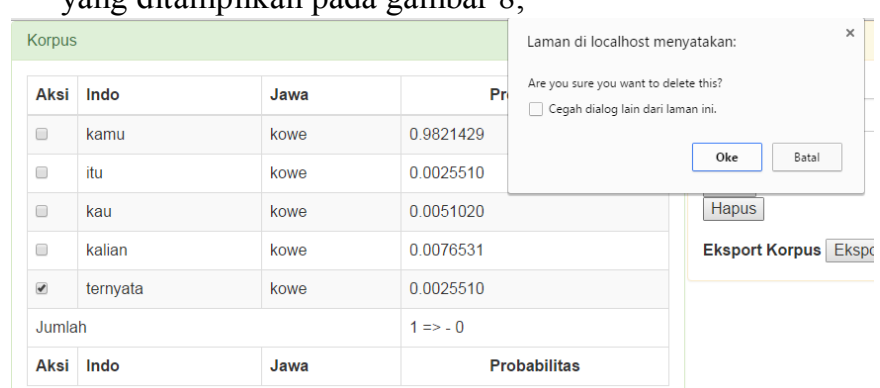

Gambar 8. Tampilan menghapus

- mengubah probabilitas kata yang tidak sesuai yang ditunjukkan pada gambar 9 .

bang-dira/coro/ubah.php - Google Chrome

䑻 bang-dira/coro/ubal $\times \square$

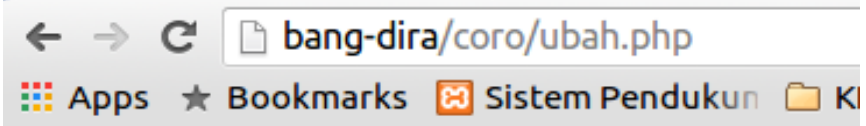

\section{Indo Jawa Probabilitas}

kau kowe 0.005105 h

kalian kowe 0.0076530

ternyata kowe 0.0025510

Kurang $\quad-0.0000030$

\section{Ubah}

Gambar 9. Tampilan mengubah

\section{E. Pengujian Ulang Hasil Terjemahan Mesin Translasi}

Langkah berikutnya adalah menguji kembali hasil terjemahan mesin translasi bahasa Jawa - bahasa Indonesia yang telah melewati perbaikan lexical model. Langkah pengujian dilakukan dengan cara melakukan pengujian otomatis yang akan memberikan output berupa korpus dalam bahasa target yang telah diterjemahkan oleh mesin dan pengujian oleh ahli bahasa.

\section{Pengujian Otomatis}

Pengujian dilakukan dengan cara membandingkan nilai BLEU hasil terjemahan otomatis dari mesin penerjemah bahasa Jawa - bahasa Indonesia sebelum dan setelah melewati tahap perbaikan probabilitas lexical model.

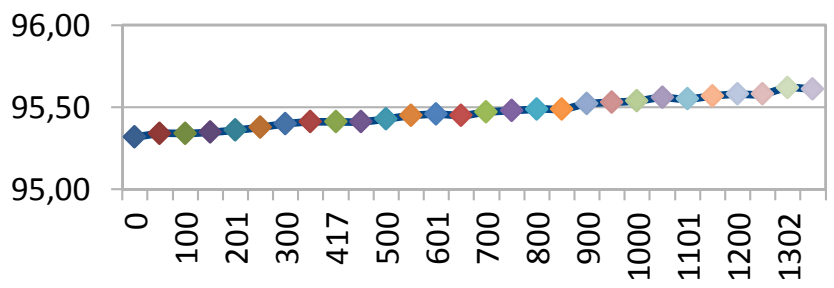

Gambar 10. Tampilan grafik nilai BLEU sebelum dan setelah perbaikan lexical model

Gambar 10 merupakan tampilan grafik sebelum mengalami perbaikan probabilitas lexical model, nilai BLEU pada korpus uji 5108 sebesar $95.32 \%$ dan setelah dilakukan perbaikan probabilitas lexical model didapat nilai BLEU sebesar 95.61\%. Terdapat peningkatan nilai BLEU sebesar $0.30 \%$ dilihat dari perbandingan sebelum dan sesudah mengalami perbaikan probabilitas lexical model.

\section{Pengujian Ahli Bahasa}

Pengujian ahli bahasa dilakukan terhadap hasil terjemahan mesin penerjemah statistik bahasa Jawa - bahasa Indonesia dengan mengambil kalimat yang mengalami perubahan pada hasil terjemahan otomatis yang terdapat pada korpus uji 5108 sebelum dan sesudah dilakukan perbaikan probabilitas lexical model sebanyak 20 kalimat. Ahli bahasa menilai apakah hasil terjemahan lebih baik, sama, atau lebih buruk berdasarkan tingkat akurasi terjemahan kata. Perhitungan akurasi dilakukan dengan Persamaan berikut :
$P=\frac{C}{R} 100 \%$
Keterangan:
$P \quad=$ Persentase akurasi
$\mathrm{C}$ = Jumlah kata yang diterjemahkan dengan tepat menurut penilaian dari ahli bahasa
$\mathrm{R}=$ Jumlah kata hasil terjemahan

Tabel 1 Tabel Akurasi Ahli Bahasa
\begin{tabular}{|l|l|l|l|}
\hline $\begin{array}{l}\text { Kalimat Hasil } \\
\text { Terjemahan }\end{array}$ & Ahli Bahasa & C,R & $\boldsymbol{P}=\frac{C}{R} \mathbf{1 0 0 \%}$ \\
\hline $\begin{array}{l}\text { Sebelum } \\
\text { Perubahan } \\
\text { Lexical Model }\end{array}$ & Sudarni, BA & $\mathrm{C}=206, \mathrm{R}=234$ & $88.03 \%$ \\
\hline $\begin{array}{l}\text { Setelah } \\
\text { Perubahan } \\
\text { Lexical Model }\end{array}$ & Sudarni, BA & $\mathrm{C}=228, \mathrm{R}=234$ & $97.44 \%$ \\
\hline
\end{tabular}

Tabel 1 merupakan tampilan tabel akurasi dari ahli bahasa sebelum mengalami perbaikan probabilitas lexical model, nilai dari ahli bahasa pada korpus uji 5108 sebesar $88.03 \%$ dan setelah dilakukan perbaikan probabilitas lexical model didapat nilai dari ahli bahasa sebesar $97.44 \%$. Terdapat peningkatan nilai BLEU sebesar $10.69 \%$ dilihat dari perbandingan sebelum dan sesudah mengalami perbaikan probabilitas lexical model.

\section{KESIMPULAN}

\section{A. Kesimpulan}

Berdasarkan hasil analisis dan pengujian, maka kesimpulan yang dapat diambil sebagai berikut.

1. Mesin penerjemah statistik dapat diimplementasikan untuk menerjemahkan bahasa Jawa ke bahasa Indonesia.

2. Berdasarkan hasil penelitian, perbaikan probabilitas lexical model dapat meningkatkan nilai akurasi terjemahan mesin penerjemah bahasa Jawa - bahasa Indonesia.

3. Persentase peningkatan nilai akurasi terjemahan mesin penerjemah bahasa Jawa - bahasa Indonesia yang dicapai sebesar $0.30 \%$ pada pengujian otomatis oleh BLEU.

4. Penilaian yang dilakukan oleh ahli bahasa menghasilkan persentase peningkatan akurasi hasil terjemahan sebesar $10.69 \%$. 


\section{B. Saran}

Beberapa saran yang dapat diberikan sebagai pengembangan dari penelitian ini adalah sebagai berikut.

1. Perlu penambahan jumlah korpus untuk meningkatkan kualitas terjemahan mesin penerjemah statistik.

2. Perlu adanya teknik dalam mencari lexical model yang diperbaiki mengingat banyaknya baris pada lexical model.

3. Perlu dilakukan penelitian lanjutan untuk melakukan analisis dalam menghasilkan terjemahan bahasa jawa ke bahasa Indonesia dengan mempertimbangkan hubungan antar frase dalam kalimat.

4. Perlu dilakukan pengujian terhadap korpus yang bukan merupakan bagian dari korpus paralel untuk mengetahui tingkat akurasi.

5. Perlu dilakukan pengecekan ulang terhadap korpus teks paralel untuk mencegah kesalahan penulisan (typo).

\section{DAFTAR PUSTAKA}

[1] Na'im, Akhsan., Syaputra, Hendri. 2010. Hasil Sensus Penduduk 2010: Kewarganegaraan, Suku Bangsa, Agama, dan Bahasa SehariHari Penduduk Indonesia. Jakarta: Badan Pusat Statistik.

[2] Republik Indonesia. 2010. Keputusan Gubernur Jawa Tengah Nomor 423.5/5/2010 tentang Kurikulum Mata Pelajaran Muatan Lokal (Bahasa Jawa) untuk Jenjang Pendidikan SD/ SDLB/ MI, SMP/ SMPLB/ MTs Negeri dan Swasta. Semarang: Pemerintah Provinsi Jawa Tengah.

[3] Hadi, Ibnu. 2014. Uji Akurasi Mesin Penerjemah Statistik Bahasa Indonesia ke Bahasa Melayu Sambas dan Bahasa Melayu Sambas ke Bahasa Indonesia. Pontianak: JUSTIN Vol 3 No 1.

[4] Manning, Christopher D., Schutze, Hinrich. 2000. Foundations Of Statistical Natural Language Processing. London : The MIT Press Cambridge Massachusetts.

[5] Sujaini, Herry., Negara, Arif Bijaksana Putra. 2015. Analysis of Extended Word Similarity Clustering based Algorithm on Cognate Language. Gujarat: ESRSA Publications Pvt. Ltd.

[6] Koehn, Philipp. 2007. Moses: Open Source Toolkit for Statistical Machine Translation. Annual Meeting of the Association for Computational Linguistics (ACL), demonstration session, Prague, Czech Republic.

[7] McEnery, T., et al. 2006. Corpus-Based Language Studies: An Advanced Resource Book. Oxon: Routledge.

[8] Hunston, S. 2002. Corpora in Applied Linguistics. Cambridge: Cambridge University Press.

[9] Papineni, K., et al. 2002. Bleu: a Method for Automatic Evaluation of Machine Translation. Philadelphia : Proceedings of the $40^{\text {th }}$ Annual Meeting of the Association for Computational Linguistics (ACL). 